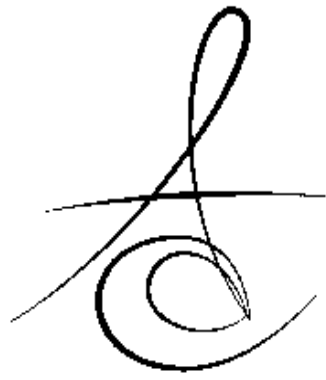

Makale Kodu/Article code: 2970

Makale Gönderilme tarihi: 27.07.2016

Kabul Tarihi: 22.11.2016

\section{SUBGİNGİVAL PLAK İÇİNDE BAKTERİYEL ETKİLEŞİMLER}

\author{
BACTERIAL INTERACTIONS IN SUBGINGIVAL PLAQUE
}

\author{
Doç. Dr. Taner ARABACI *
}

\section{öz}

Periodontitis polimikrobiyal bir hastalıktır. Araştırmacllar uzun dönem mikrobiyal kompleksleri redüksiyonist bir yaklaşımla incelemişlerdir. Yani mikroorganizmaları mikrobiyal kompleksten ayırıp bireysel olarak inceleyerek oral mikrobiyal patogenezden sorumlu temel patojenleri belirlemeye çalışmışlardır. Ancak sonradan farklı mikroorganizmalar arasındaki etkileşimin bireysel olarak elde edilemeyecek birçok yeni fizyolojik fonksiyonun oluşmasına neden olduğunu görmüşlerdir. Bunun üzerine türler arasındaki etkileşimler, mikrobiyal topluluk polimikrobiyal hastalıklar gibi konulara ilgi artmışıı. Araştırmaların yönü parçaların tamamını yani bütünü kavramaya yönelmiştir. Fiziksel ilietişim birbirini takip eden mikroorganizmalara tutunma sahası sağlar, metabolik iletişim lokal çevrenin patojenlerin büyümesi için uygun hale getirilmesine yardımcı olur; sinyal molekülleri bakterilerin çevresel değişiklere cevap olarak verdikleri davranışları düzenler. Genetik iletişim antibiyotiklere karşı mikrobiyal direncin oluşmasını sağlar. Türler arası iletişim periodontal hastalıkların başlaması ve ilerlemesinde major rol oynar. Bu derlemenin amacı türler arası etkileşim senaryolarını derlemektir.

Anahtar Kelimeler: Subgingival Plak, Bakteriyel Etkileşimler, Periodontitis

\section{GİRİŞ}

Mikrobiyolojik araştırmalar van Leeuwenhoek tarafından geliştirilen ilk mikroskopla bakterilerin incelenmesi ile başlamıştır. ${ }^{1}$ İlk incelediği örneklerden birisi kendi dental plak veya biyofilmidir. Oral mikrobiyolojinin gelişiminde ise W.D.Miller oral hastalıkların etiyolojisinde mikroorganizmaların rolü üzerinde çalışmıştır. 2

\section{ABSTRACT}

Periodontitis is a polimicrobial disease. For a long time, researchers investigated microbial complexes with a reductionist approach. They extracted microorganism from microbial complex and searched individually to predefine the key pathogens responsible from oral microbial pathogenesis. The interaction of different microorganism observed in many new physiological functions which can not be observed induvidually. Upon this increased interested in topics such as interspecies interaction, microbial community and polimicrobial diseases. Physical communication procures the adherence site to the consecutive microorganisms; metabolic communications cause the suitable local environmental changes for the growth of pathogens, signaling molecules help bacteria to regulate their behavior in response to changes in the environment. Genetic communication ensures the microbial resistance against the antibiotics. Interspecies communication plays a major role in the initiation and progression of periodontal disease. The aim of this review is compiled the scenarios interspecies interaction.

Key Words: Subgingival Plaque, Bacterial İnteraction, Periodontitis.

Mikroskobun bulunması ile daha gerçekçi araştırmalar yapılabilmiştir. Oral kaviteden izole edilen yaklaşık olarak 280 bakteri türü kültüre edilebilmektedir. ${ }^{3}$ Bununla birlikte oral kavite birçoğu biyofilmde yaşayan 500 'den fazla türe ev sahipliği yapmaktadır. ${ }^{4}$

Tek bir türün neden olduğu mono-mikrobiyal karakterdeki birçok hastalık kültürle ilişkili izolasyon teknikleri kullanılarak tanımlanmıştır. Kültürden bağımsız organizma topluluğu analizlerinin gelişmesi

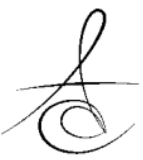


ile ortaya çıkan $16 \mathrm{~S}$ rRNA ve metagenomik sekans metadolojileri özellikle kronik karakterdeki bazı hastalıkların polimikrobiyal doğaya sahip olduğunu göstermiştir. Periodontitis de polimikrobiyal karakterde kronik enfeksiyöz bir hastalıktır. ${ }^{6}$ Genel görüş oral biofilmin oral sağlık ve hastalıklarda rol oynadığı yönündedir. Diş ve dişetlerinin hastalıklarından olan diş çürüğü ve periodontitis dental plaktaki polimikrobiyal etkileşimle ilişkilendirilmiştir. ${ }^{?}$

Araştırmacılar uzun dönem mikrobiyal kompleksleri redüksiyonist bir yaklaşımla incelemişlerdir. Yani mikroorganizmaları mikrobiyal kompleksten ayırıp bireysel inceleme yoluna gitmişler ve oral mikrobiyal patogenezden sorumlu temel patojenleri belirlemeye çalışmışlardır. ${ }^{8}$ Redüksiyonizmin limitasyonları araştırmacıları yeni stratejiler geliştirmeye zorlamışıı. Bunun üzerine türler arasındaki etkileşimler, mikrobiyal topluluklar, polimikrobiyal hastalıklar gibi konular üzerinde durulmuştur. Araştırmaların yönü parçaların tamamını yani bütünü kavramaya yönelmiştir. Farkı komponentlerin arasındaki etkileşim bireysel olarak elde edilemeyecek birçok yeni fizyolojik fonksiyonun oluşmasına neden olmuştur. Bu derlemenin amacı türler arası etkileşim senaryolarını derlemektir.

\section{Subgingival Plakta Bakteri Metabolizması ve Periodontal Hastalık}

Dişeti kenarına göre lokasyonu gözönüne alındığında dental plak dişeti seviyesinin üzerindeki supragingival plak ve dişeti seviyesi altındaki subgingival plak olarak ikiye ayrilır. ${ }^{7}$ Supragingival plak diş yüzeyine tutunan diş çürüğü ile ilişkilendirilen gram pozitif mikroorganizmaların baskın olduğu bir yapıdır. ${ }^{\stackrel{ }{2}}$ Subgingival plak ise periodontal cep içerisinde periodontitisle ilişkilendirilen gram negatif mikroorganizmaların baskın olduğu bir yapıdır. ${ }^{10}$ Hastalı̆ı̆n tedavisi ve hastalıktan korunmada dental plağın uzaklaştırımasının öneminin ilk kez vurgulayan W.D.Miller olmuştur. ${ }^{11}$

\section{Biyofilm}

Biyofilmler kendileri tarafından üretilen exrasellüler matrix içerisindeki mikroorganizmaların birbirlerine veya bir yüzeye organize olmuş bir şekilde tutunmaları olarak tanımlanabilir. ${ }^{12}$ Biyofilm hastalık ve sağlık durumunun oluşmasında çok önemli rollere sahiptir. $\cdot \underline{13}$

Biyofilm formasyonu sıralı kazanılmış pelikıl formasyonu, primer ve sekonder kolonizerlerin kolonizasyonunu kapsayan oldukça düzenli ve koordineli bir süreçtir. (Şekil 1)

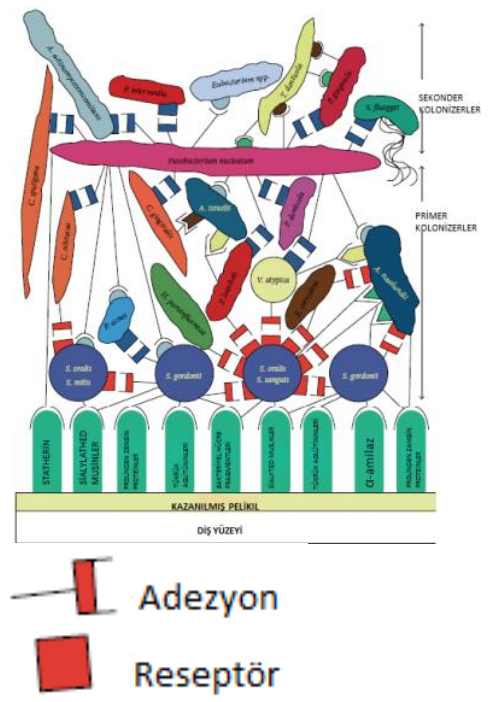

Şekil 1. Dental plaktaki bakterilerin birbirlerine tuntunmaları ve kümelenmeleri şematik olarak gösterilmiştir. Primer kolonizerler kazanılmış pelikıldaki reseptörlere bağlanırlar. Sekonder kolonizerler ve diğer primer kolonizerler de bu hücrelerin reseptörlerine adezyon moleküller ile bağlanır. $\underline{14}$

Araştırmacılar bakteri topluluklarının birbirleriyle iletişim halinde olduklarına dair güçlü verilere ulaşmışlardır. Diş yüzeyi, temizliği yapıldıktan saniyeler sonra konak kaynakı çeşitli moleküller ile kaplanarak kazanılmış pelikıl oluşur ve Streptococcus türleri, Actinomyces türleri, Capnocytophaga türleri, Eikenella türleri, Haemophilus türleri ve Veillonella türleri gibi primer kolonizerler için reseptör görevi görür. ${ }^{14}$ Primer bakteriler diğer bakteriler için spesifik reseptöre sahiptirler. Bakteriler mısır koçanı ve fırçaya benzeyen şekilde olgun biofilmde koagrege olurlar. Koagregasyon deği şik genetik yapıdaki hücrelerin birbirini tanıması şeklinde tanımlanabilir. Fusobacterium nucleatum, Treponema türleri, Porphyromonas gingivalis türleri ve Aggregatibacter actinomycetemcomitans ikincil kolonizerler arasındadır. $\frac{15}{}$ Biofilm olgunlaştıkça mikrobiyal komponentlerde kayma gerçekleşir. Streptococcus ve Neisseria sayısı azalırken Actinomyces, Corynebacterium, Fusobacterium, ve Veillonella sayısı artar.

Fusobacterium nucleatum'un plak maturasyonunda çok önemli bir rolü olduğu düşünülmektedir. ${ }^{16}$ Fusobacterium nucleatum birbirlerine doğal olarak bağlanamayan bakteriler arasında koagregasyon köprüsü oluşturur. 


\section{MİKROBİYAL İLETİŞİM}

Başarılı bir organizasyon için iletişim anahtar unsurdur. Oral florada 500 'den fazla tür bakteri vardır. Bunlardan bazıları kommensal bazıları da patojeniktir. Oral bakteriler birçok bakteriyel türden oluşan topluluklar içinde spesifik partneri ile metabolik ve kimyasal iletişim gösterir. $\stackrel{17}{ }$ 는 Oral biofilmdeki birçok türün bireysel olarak işlev görmesi mümkün değildir, bu organizmaların fonksiyonu tür içi ve türler arası iletişimi koordine etmektedir. Bakteriler oral biofilmin inşa edilmesinde birinin diğeriyle iletişiminde özel roller üstlenirler. Adherent bakteriler dental gelişimi süresince komşusunu etkileyerek uygun cevabın oluşumunu sağlarlar.

Besinlerin Biyofilm İçindeki Bakterilerin Türler Arası Etkileşimlerindeki Rolü

Biyofilmin bakteriyel kompozisyonunun belirlenmesinde en önemli faktör uygun besindir. Öğünlerde alınan yiyecekler, tükürük ve dental plaktaki diğer organizmaların ürettiği polisakkaritler gibi besinler oral biyofilmdeki bakteriler için besin kaynağıdır. 19

P.gingivalis periodontal hastalıklarda majör etiyolojik ajandır, sıkıkla diğer periodontopatojenler olan P.intermedia, F.nucleatum, T.forsythia ve T.denticola ile birlikte yer alı. ${ }^{20}$ Grenier ${ }^{21}$ P.gingivalis ve T.denticola arasında bir çapraz beslenme olduğunu göstermişlerdir. İkisinin komşu kültürlerde geliştiği bir durumda P.gingivalis T.denticola tarafindan üretilen süksinatı metabolize ederek büyümesini destekleyebilir. Buna ek olarak P.gingivalis izobütirik asit üreterek T.denticolanın büyümesini stimüle eder. (Şekil 2)

Biyofilmdeki iki organizma arasında sinerjistik veya mutalistik etkileşim Actinomyces naes/undii ve Streptococcus oralis arasında gösterilebilir. ${ }^{22} \mathrm{Her}$ iki organizma da tükürükle kaplı yüzeye ayrı ayrı zayıf bir kolonizasyon sergilerlerken birlikte olduklarında ise aynı yüzeyde geniş bir biyofilm şeklinde olurlar. Bu durum iki organizmanın tükürük komponentlerinin metabolize edilmesinde kombine metabolik aktivite sergilemeleri nedeniyle oluşmaktadır.

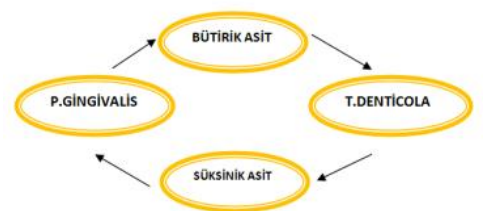

Şekil 2. P.gingivalis bütirik asit üreterek T.denticolanın büyümesini stimüle eder. T.denticola da ürettiği süksinik asitle P.gingivalisin büyümesini destekler.

\section{ORAL BİYOFİLMDE MEKANİK VE KİMYASAL İLETİ̧̧̇̇M \\ 1.FİZİKSEL İLETİŞİM \\ Dental plağın oluşumu ve maturasyonunda} majör role sahiptir. Kazanılış pelikıl yüzeyi kaplar ve plaktaki primer kolonizerler için bir reseptör rolü oynar. Primer kolonizerler, sekonder kolonizerlerin bağlanması için reseptör sağlarlar. 14

\section{METABOLİK İLETIŞ̧̇̇M}

Biyofilmin temelinde koagregasyon vardır. Bakteriler komşu hücrelerin sebep olduğu lokal çevrelerindeki değişikliklerden etkilenirler, bu yolla mikrobiyal popülasyonun ekolojik çevresi hakkında bilgi alırlar. Bilgiyi gönderenler bilgiyi alanlarda gen expresyonuna neden olarak fenotipte değişikliklere neden olurlar. $\frac{18}{}$

\section{Genel Metabolik Ürünlerin Biyofilm Sakinlerinin Etkileşimine Etkileri}

Bir organizmanın sekonder metabolitlerinin aynı biyofilm içinde yer alan başka bir organizma üzerinde de etkisi olur. Örneğin eğer dental plak içerisinde S.mutans oranı yüksek ise S.sanguinis türleri düşük oranda bulunur. ${ }^{23}$ Çünkü S.mutans türleri S.sangiunis üyelerinden daha asidüriktir ve laktik asit üretimi S.mutansín büyümesini destekler. Diğer taraftan S.sangiunis da S.mutans gibi diğer komşu bakteriler için antimikrobiyal özellikte olan hidrojen peroksit üretimi yapar, bu toksik maddeyi metabolize edecek sisteme sahip olmayan bakteriler için bu yıkıc bir moleküldür. Ayrıca periodontitisle ilişkilendirilen birçok anaerobik bakteri antioksidanlara karşı hassastır. ${ }^{24} \mathrm{Bu}$ nedenle dental plakta S.sanguinis oranı yüksek seviyede ise S.mutans veya periodontopatojenik mikroorganizmalardan P.gingivalis'in oranı düşüktür. ${ }^{25}$ Dental plakta S.sanguinis üyeleri mevcutsa bu durumda genelde periodontopatojenlerin seviyesi düşüktür ve oral sağlık iyidir. $\underline{25}$ Streptokokal $\mathrm{H}_{2} \mathrm{O}_{2}$ oral bakteriler arasında yarış ve iletişimde önemli bir moleküldür. (Şekil 3) Stacy ${ }^{26}$ fare apse infeksiyon modellerinde A.actinomycetemcomitans için kommensal S.gordonilnin sinerjik virülans sağladığı göstermiştir. S.gordonii A.actinomycetemcomitans'ın kullanacağı laktat ve karbon kaynağını sağlamakla birlikte onun için zararlı olan hidrojen peroksidi üretir. Bu nedenle A.actinomycetemcomitans hidrojen peroksidin öldürücü etkisinden korunacak kadar ancak laktattan da yararlanabilecek bir pozisyonda olacak şekilde kendi konumunu belirler. 


\section{Viridans streptoc}

Şekil 3. Viridans streptococci ürettiği $\mathrm{H}_{2} \mathrm{O}_{2}$ bazı bakteriler için yıkıcı bir molekül iken A.a gibi bazı bakterilerin konak defans mekanizmalarını yenmesini kolaylaştırarak hayatta kalmasına yardımcı olur. $\underline{70}$

Bunların aksine bir organizmanın metabolik ürünü bir diğerinin büyümesini destekleyebilir. Oral kavitede en bol bulunan Streptococci türleri gıdalardan veya tükrükten elde ettikleri glikoproteinleri laktat, asetat ve formete çevirir bu da diğer türlerin yaşaması için uygun olan düşük pH'ılı bir ortam S.mutans tarafından üretilen laktik asit Veillonella ailesi üyeleri tarafından metabolize edilebilir. ${ }^{27}$ Veillonella türlerinin dental plak gelişiminin erken aşamalarında görünmesinin bu durumla ilgili olduğu öne sürülmektedir. Streptococci ve Veillonella türleri arasındaki iletişim metabolik gereksinimler sonucu oluşur. ${ }^{28}$ (Şekil 4)

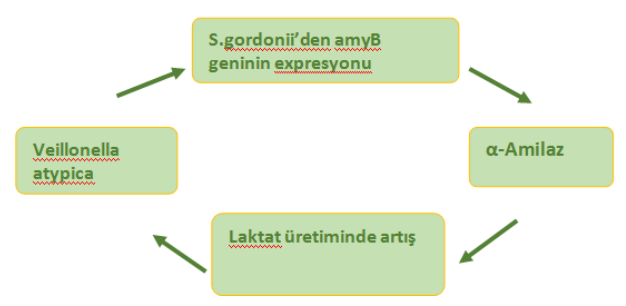

Şekil 4. Veillonella atypica S.gordonii'de bazı genlerin expresyonunu uyararak metabolik ihtiyacı olan laktatı karşılar..$^{28}$

Metabolik ürünler yoluyla bakteriler arası etkileşime bir diğer örnekte gaz metabolizmasıdır. Bu etkileşime oksijen ve karbondioksit metabolizmasını örnek verebiliriz. Zorunlu anaerob bakteriler arasında periodontitise sebep olan bakteriler oksijen konsantrasyonunun yüksek olmadığı ortamlarda prolifere olabilirler. Bu nedenle oksijeni metabolize eden organizmaların ortamda bulunmaları bu bakterilerin büyümesini destekler. P.gingivalis için optimum $\mathrm{pH}^{\prime \prime} ı$ olduğu bir mikroçevrenin devamlılığı ve P.gingivalis'in üreyebilmesi için F.nucleatum tarafından pH'ın azaltılmasını ve kapnofilik çevrenin üretilmesi gerekmektedir. $\underline{29}$

Hem F.nucleatum hem de P.gingivalis zorunlu anaerob olmalarına rağmen oksijene olan duyarlılıkları birbirinden oldukça farklıdır. P.gingivalis oksijene çok hassasken F.nucleatum \%20 sevilerine kadar oksijeni tolere edebilir. İlginçtir ikisi aynı ortamda kültüre edildiklerinde ise P.gingivalis de \%20'lik oksijenli ortamda yaşayabilir. Bu muhtemelen F.nucleatum'un aktif
NADH oksijen/peroksidaz aktivitesi yoluyla hem moleküler oksijeni hem de hidrojen peroksidi metabolize edebilmesi ve P.gingivalis için oksijeni azaltacak şekilde mikroçevreyi düzenlemesi nedeniyledir. Aynı zamanda F.nucleatum, P.gingivalis'in büyümesi için gerekli olan karbondioksit intiyacını da karşılamaktadır. $\underline{29}$ (Şekil 5)

\section{Eusobacterium nucleatum $\Rightarrow$ Kaonofflik ortam sä̈lar. $\Rightarrow \begin{aligned} & \text { P.gingivalis'in büyümesini } \\ & \text { destekler. }\end{aligned}$}

Şekil 5. F.nucleatum aktif NADH oksijen/peroksidaz aktivitesi yoluyla P.gingivalisin büyümesi için gerekli olan anaerobik ortamı, oksijeni tüketip karbondiokit üreterek sağlar. $\underline{29}$

Yapılan gözlemlerde ortak metabolik etkileşimle belli bakterilerin lokal mikroçevreyi modifiye ederek diğer türlerin büyümesi için elverişli hale getirebildikleri gösterilmiştir. Örneğin F.nucleatum ve P.intermedia pH 5.0 ila 7.0 gibi geniş bir aralıkta yaşayabilirler ancak P.gingivalis $\mathrm{pH}^{\prime} ı$ n $6.5^{\prime}$ in altında düşmesine karşı hassastır. Takahashi ve ark'nın çalışmasında F.nucleatum ve P.intermedia tükürük ve dişeti oluğu sıvısında yer alan temel aminoasitlerden aspartik asit ve glutamik asidi fermente eder ve amonyuma çevirirler. $\underline{30}$ Bu dental plakta laktik asit bakterileri ve fermantasyon yapabilen bakterilerin varlığında $\mathrm{pH}$ 'da ciddi düşüşleri engeller böylece aside duyarlı olan P.gingivalis'in organik asit ataklarından korunacağı nötral bir çevre oluşturmuş olurlar. ${ }^{30}$ Actinomyces naes/undii birincil kolonizer bir bakteridir ve birçok bakteri türünü hidrojen peroksitten korur. (Şekil 6)

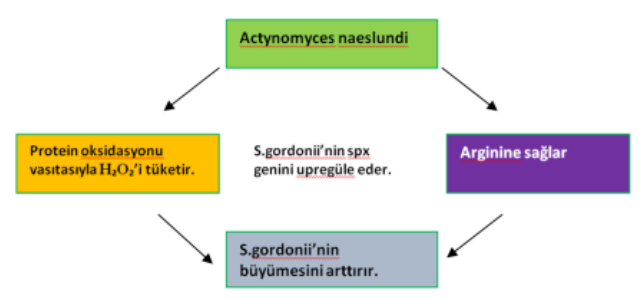

Şekil 6. Actynomyces naeslundi ve S.gordonii arasındaki metabolik iletişim ${ }^{58}$

\section{Bakteriyel Etkileşimlerin Etkilediği Diğer Biofilm Özellikleri}

Gibbons ve ark.'ları 13 bir çalışmalarında, birçok oral bakterinin birbirleriyle koagrege olduğu öne sürmektedirler. Örneğin P.gingivalis suşlarının birçok oral streptokokla kümelendiğini göstermişlerdir.

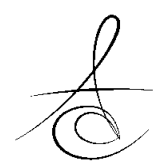


P.gingivalis ve oral streptokoklar koagrege olarak biyofilm içinde birbirlerinin kolonize olma kabiliyetlerini arttııılar. Araştırmacılar bazı organizmaların biyofilmde kendi başlarına bulunamadığını en azından potansiyel partner ile birlikte yer alabildiğini göstermişlerdir. T.denticola inert yüzeylerde biyofilm içinde bulunmazken P.gingivalis kolaylıkla yer alır. ${ }^{32}$ Ancak P.gingivalisín varlığında Treponema biofilm içine dahil olabilir. Ayrıca T.denticola Benzer şekilde periodontopatojenlerden T.forsythia inert yüzeylere zayıf kolonize olurken F.nucleatum varlı̆ı̆nda biofilme dahil olur. $\frac{33}{}$ Rat periodontitis modelde P.gingivalis ,T.denticola ile birlikte aşılandığında tek başına aşılandığından daha önemli miktarda kemik yıkımına neden olmuştur. ${ }^{34}$

Birçok çalışmada biyofilm bakterileri arasındaki etkileşimin biyofilmdeki bakterilerin antimikrobiyal hassasiyetlerini etkileyebildiği öne sürülmüştür. Bu sonuçlarda $\mathrm{CHX}$ 'in antimikrobiyal etkinliğine karşı S.mutans ve Veillonella parvula'nın birlikte olduğu zaman bireysel olduklarından daha dirençli oldukları gösterilmiştir. Bu direncin moleküler temelleri belirlenememiştir, bu iki mikroorganizmanın birlikte kümelenmesi nedeniyle bu özelliğin oluştuğu düşünülmektedir. $\underline{11}$

Diğer bir örnekte S.mutans ve S.gordonii arasındadır. Bu iki kommensal streptokok normalde dental plakta ters orantilı olarak bulunur. $\frac{35}{5}$ S.gordonii S.mutansín kompetans stimüle edici peptidini competance stimulating peptide (CSP) inaktive ederek çok sayıda quorum sensing ile ilişkili mekanizmasını antogonize edebilir. ${ }^{36} \mathrm{Bu}$ nedenle biofilmde S.gordonii varlığı S.mutans'ın tükrükte bulunan histatin gibi antimikrobiyal ajanlara karşı hassasiyetini arttırarak antogonist etki yapabilir. Buna ek olarak CSP'nin inaktive edilmesi ile S.mutans'ın birçok antimikrobiyal ajana karşı direnci azaltılmaktadır.

Birçok hayvan modelde 2 veya daha fazla farkı oral bakteriyel türün arasındaki sinerji bakterilerin virulanslarını arttıır. P.gingivalis ve T.forythia ile infekte olan farelerin apselerinde çok büyük lezyonlar gelişmiştir ve bu iki mikroorganizmanın tek başına bulunduğu lezyonlardan daha mortal seyirli olmuştur. 37 Ayrica fare apse modellerinde P.gingivalis ve F.nucleatum $^{38}$, P.gingivalis ve T.denticola ${ }^{39}$ ve $P$.gingivalis ve A.actinomycetemcomitans ${ }^{40}$ arasında da sinerjik etki olduğu rapor edilmiştir.

Bakteriler ayrıca diğer bakteriler üzerinde spesifik ve non-spesifik etkisi olabilen ürünler üretebilir.
Bunlardan spesifik etkisi olanlara bazı bakterilerden exprese edilen bakteriyosinler örnek olarak verilebilir. Bakteriyosinler proteinimsi toksinlerdir ve bütün majör bakteri türlerinde bulunur. Bunlar geleneksel antibiyotiklerin aksine dar spektrumludurlar, sadece ilgili mikroorganizmanın büyümesini inhibe ederler. ${ }^{41}$ S.mutans suşları çok sayıda farklı bakteriosin ve mutasin üretir. ${ }^{42}$ S.mutans farklı 5 bakteriyosin ve mutasin üretebilir. Mutasin 1, 2 ve Mutasin 3 lantionin içeren lantibiyotik üyesi nispeten geniş antimikrobiyal spektrumlu iken Mutasin 4 ve 5 lantibiyotik değildir. Birçok çalışmada S.mutans ın mutasin aktivitesi sayesinde dental biyofilmde varlığııı başarılı bir şekilde devam ettirebildiği öne sürülmüştür. S.mutans'ın üretiği bazı bakteriosinlerin S.sanguinisin büyümesini inhibe etmesi nedeniyle S.mutans'ın yoğun olduğu du- rumda S.sanguinišin düşük oranda olduğu düşünülmektedir..$^{43}$

Baktriosinler ayrıca sinyal moleküllerinin anologları olarakta türler arası etkileşimi etkileyebilir. Örneğin, Streptococcus pyogenes ve Streptococcus salivariusún ürettiği lantibiyotik bakteriosinler yapısal olarak benzerdir ve bu iki komponentin sinyal sistemleri etkileşir. ${ }^{44}$ Her ikisi de mukozal yüzeylerde kolonize olurlar ve büyümeleri için gerekli olan sinyallerin antogonistlerini üreterek birbirlerinin büyümelerini inhibe ederler. Böylece kommensal S.salivarius suşları biofilmi virulant olan S.pyogenes suşlarından korumuş olur.

Antimikrobiyal ajanlardan başka bacteriocinlerin de bazı bakterilerin sinyal transdüksiyon sistemleri üzerinde etkilerinin olduğu öne sürülmektedir. ${ }^{45}$ Bu ajanlar büyümeyi inhibe etme karakterinde antibiyotiklerdir

Birçok oral bakteri diğer bakterilerle yarışta bakteriyosin benzeri içerikleri kullanmaktadır. Teanpaisan ve ark periodontal sahadan izole ettikleri P.gingivalis, P.internedia, Provotella nigrescens gibi siyah pigmentli bakterilere ait 44 suşu bakteriyosin üretimi, sensitivitesi ve aktivitesi açısından incelemişlerdir. ${ }^{46}$ P.nigrescens'in P.gingivalis, P.intermedia, T.forsythia ve Actinomyces türleri için bakterisidal etkinliği olan bir bakteriyosini ürettikleri görülmüştür. ${ }^{47}$

P.intermedia $\underline{48}$, Capnocytophaga ochracea $\underline{49}$, A. Actinomycetemcomitans $\frac{50}{}$, Haemophilus influenzae $\underline{51}$, F. nucleatum $\underline{52}$ ve E. Corrodens $\underline{53}$ gibi diğer bakterilerinde bakteriyosin ve bakteriyosin benzeri aktiviteye sahip oldukları rapor edilmiştir. Ancak biyokimyasal özellikleri ve genetik determinantları iyi karakterize edilememiştir. T.denticolada en az 3 çeşit bakteriyosin sekresyon sistemi ortaya çıkarılmışır. $\frac{54}{}$ 
Moleküler ve genetik çalışmalardan elde edilen verilere göre bakteriyosin üretimi hem hücre yoğunluğu, besin mevcudiyeti ve pH gibi çevresel faktörlere hem de genetik faktörler gibi regülatör sistemlere bağlıdır. $\underline{55}, \underline{56}$ Mikrobiyal topluluğun stabilitesi aynı biyolojik niş içerisindeki farklı türler arasında doğal dengenin kurulmasıyla sağlanabilir. Oral bakteriler arasında belli bakteriyosin ve bakteriyosin benzerlerinin üretim ve sensitivite aktiviteleri etkin olan bakteriler komşularını seçerek spesifik bakteriyel türlerden oluşan bir birliğin kurulmasını destekler ve oral ekosistemin ekolojik dengesinde önemli bir rol oynarlar. $S$. mutans ve $S$. sanguinis sayıları ters orantılıdır. S.Mutans, $S$. sanguinis 'un büyümesini yüksek miktarlarda organik asit ve mutasin üreterek inhibe eder. ${ }^{43}$ (Şekil 7)

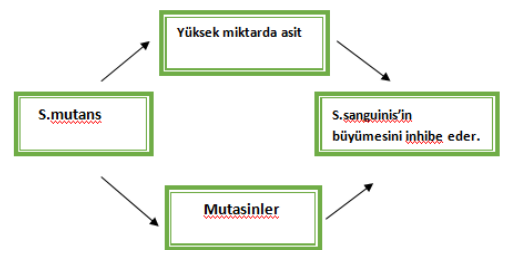

Şema 6: S. Mutans, S. sanguinis 'un büyümesini yüksek miktarlarda organik asit ve mutasin üreterek inhibe eder. ${ }^{43}$

\section{HORİZONTAL GEN TRANSFERİ}

Horizontal gen transferi birçok bakteriyel genomun moleküler gelişiminde önemli katkıya sahiptir. ${ }^{57}$ Biyofilm içindeki yoğun populasyon yapısı türler arasında gen transferi imkanını arttııı, böylelikle de avirulan olan patojen güçlü virulan bir patojene dönüşür. Birçok bakteri türü arasında konjugatif transpozonlar ve insersiyonların gerçekleşmesi vasıtasıyla horizontal gen transferi olduğuna dair kanıtlar vardır. Örneğin S.mutans 'ın TnSmull transpozonuna sahip olduğu gösterilmiştir. $\underline{58}$

Konjugasyon: Direkt hücre-hücre teması ile genetik materyalin polar transferidir. Örneğin;

- A. comitans suşları arasında ve A.actinomycetemcomitans ile $\mathrm{H}$. influenza arasında A.Tet(B) gen transferi mevcuttur. ${ }^{59}$ ( tetrasiklin direnci sağlar)

- Eğer C.albicans biofilmde mevcutsa S.gordonii arasında horizontal gen transferi gerçekleşir ve S.gordonilnin bakteriosin ve mutasin üretmesini sağlar. $\frac{60}{}$

- Tn916 antibiyotik rezistansı ile kodlanmıştır, oral streptokoklar arasında transfer edilmektedir. $\underline{61}$

Transformasyon: DNA nakli ve DNA onarımı olarak tanımlanır. Örneğin;

1. S.mutans'lar arasında eritromisin direnci geninin transferi $\underline{62}$

2. T. denticola ve $S$. gordonii arasında türler arası gen transferi. $\underline{63}$

Transdüksiyon: Bakteriyofajlar aracilığıyla gen transferi birçok non-patojenik bakterinin lizojenik konversiyonuna neden olur. Örneğin Tn916 ve pkT210 A.actinomycetemcomitans suşları arasında Aaø23 fajı aracılığıyla taşınmaktadır. $\underline{64}$

\section{Sensing}

Kimyasal Ajanların Sinyalleri ve Quarum

Quarum Sensing (QS) bakteri yoğunluğunun ve ekolojik şartların değişmesine cevaben bir veya daha fazla ajanın kendiliğinden indüklenen sekresyonu ve gen expresyonunu başlatarak grup veya hücre davranışlarına yön vermesidir. QS sistemleri bakteriyel hücre adezyonu, extrasellüler matrix üretimi, kompetans(yeterlilik) da dahil pek çok cevabı kontrol eder. $\underline{65}$ QS mekanizması sırasında bakteriler "autoinducer" adını verdikleri bir kimyasalı salglıyarak birbirleri ile iletişim kurarlar. Autoinducer 2(Al-2) de bunlardan biridir ve LuxS geninin expresyonu ile salgilanır. ${ }^{66}$

LuxS S. mutans, S. gordonii, S. oralis, and $P$. gingivalis gibi birçok bakterinin genomunda olan bir sekanstır. Al-2 geniş çaplı olarak gen expresyonunda değişikleri indükler. Al-2 hem tür içi hem de türler arası sinyal olarak rol oynar. P. gingivalis 'den A.a'ya Al-2 sinyalinin olduğu bir çalışmada gösterilmiş, böylelikle Al-2 kullanılarak türler arası komünikasyonun olduğuna dair ilk kanıt elde edilmiştir. A.oris ve S.oralis 'den teşekkül eden iki türün oluşturduğu biyofilm çalışmalarında Al-2'nin önemli bir fonksiyonu olan mutualistik ilişkisi gösterilmiştir. Kommensal oral bakteriler düşük seviyede Al-2'ye cevap verirken periodontopatojenler yüksek seviyede Al-2'ye cevap verir. Plak maturasyonu sırasında bakteri çok daha yüksek seviyelerde Al-2'i hem alır hem de gönderir, kommensal bakterilerin büyümesinde azalma olur. $\underline{67}$

Competence stimulating peptide (CSPs) genetik kompetansı(yeterlilik), biyofilm formasyonunu ve bakterilerin asit toleransını regüle eder. CSPs yaklaşık olarak 17-21 aminoasitten oluşan kısa peptitlerdir. 
comC gen ürünlerinin proteolitik sindirimi sonucu birçok streptokok türü tarafından üretilir. CSPs intersellüler sinyaller olan ve olumsuz çevresel faktörler nedeniyle çok yönlü mesajlar yaymak için üretilen alormonesleri indüklerler. CSPs oral streptokoklar üzerinde çeşitli etkilere sahiptir bunlar arasında kompetansı destekleme, biyofilm formasyonu ve DNA expresyonu vardır. S.mutans'lardaki CSP-sensing yolağı çeşitli oral bakterilerin antimikrobiyal aktiviteleri olan mutasinler ve bakteriyosinlerin üretimi ile bağlantılıdır. CSP molekülleri yüksek oranda türe spesifiktir. Bir bakteri tarafından üretilen CSP nadiren başka bir bakteri tarafindan üretilen bir CSP'nin aktivitesine müdahale eder. Eckert ve ark CSP'nin doğasındaki türe spesifikliği kullanarak çok özel bir antibakteriyel ajan geliştirmişlerdir, bu ajana Spesifically Targeted Antimicrobial peptides (STAMPS) ismini vermişlerdir. Böylelikle hedefe özel antibakteriyel karakterde bir ajan geliştirmiş̧lerdir..$\underline{68}$

\section{Türler arası Etkileşim ve Periodontal Hastalık}

Periodontal hastalıkların ana sebebi dental plak "serum, tükürük, kan ürünleri ve bakteriyel metabolik ürünlerden oluşan exrasellüler matrix içine gömülü çeşitli türler ve suşların diş ve restorasyonların üzerinde sıralı olarak kolonizasyonu ve büyümesi sonucu oluşan yapısal birim" olarak tanımlanabilir.

Dental plak içindeki mikroorganizmalar kompleksler halinde bulunur. Şu an farkı mikrobiyal kompleksler tanımlanmışıı ve hastalığın başlangııının ve ilerleyişinin farklı aşamalarıyla ilişkili olduğuna inanımaktadır. Sarı kompleks, mor kompleks üyeleri dental plağın erken kolonizerleridir. Yeşil, turuncu ve kırmızı kompleks dental plağın sekonder kolonizerleridir. Yeşil ve turuncu kompleks üyelerinin periodontal veya periodontal olmayan infeksiyonların muhtemel sebebi olabileceği kabul edilmektedir. Kırmızı kompleks sondalamada kanama ile ilişkilidir. Turuncu kompleks bakterileri kırmızı kompleks bakterileri ile ilişkilidir, hastalıklı sahalarda ve ileri periodontal hastalıkta sayıca yüksek oranda bulunur. ${ }^{69}$ Bu nedenle aynı veya farklı bakteri kompleksleri arasında dayanışma olduğu için etkili bir iletişim mekanizması esastır.

\section{SONUÇ}

Farklı bakteriyel türler arasındaki iletişimhayatta kalım şanslarını arttıır. Periodontal hastalıkların etyopathogenezinde major rol oynar. Fiziksel iletişim ardışık mikroorganizmalara bağlanma sahası sağlar, metabolik iletişim patojenlerin büyümesi için çevresel değişikleri beraberinde getirir, sinyal molekülleri çevresel değişiklere cevap için bakterileri davranışlarını düzenlemede bakterilere yardımcı olur. Genetik iletişim antibiyotiklere karşı mikrobiyal direncin oluşmasını sağlar. Türler arası iletişim periodontal hastalıkların başlaması ve ilerlemesinde major rol oynar.

\section{KAYNAKLAR}

1. Gest H. The discovery of microorganisms by Robert Hooke and Antoni Van Leeuwenhoek, fellows of the Royal Society. Notes Rec R Soc Lond, 2004, 58: 187-201.

2. WD. M. Graphische Anstalt Schuler AG. The microorganisms of the human mouth. Biel, Switzerland: 1890.

3. Paster BJ, Boches SK, Galvin JL, Ericson RE, Lau CN, Levanos VA, Sahasrabudhe A, Dewhirst FE. Bacterial diversity in human subgingival plaque. J Bacteriol, 2001, 183: 3770-3783.

4. Dewhirst FE, Chen $T$, Izard J, Paster BJ, Tanner AC, Yu WH, Lakshmanan A, Wade WG. The human oral microbiome. J Bacteriol, 2010, 192: 50025017.

5. Peters BM, Jabra-Rizk MA, O'May GA, Costerton JW, Shirtliff ME. Polymicrobial interactions: impact on pathogenesis and human disease. Clin Microbiol Rev, 2012, 25: 193-213.

6. DG. ÇC. Tumour Necrosis Factor Alpha Levels In Gingival Crevicular Fluid Of Periodontitis Patients With/Without Mtdna Deletion In Gingival Tissue. Atatürk Üniv Diş Hek Fak Derg 2014, 24(2): 170177.

7. Nishihara T, Koseki T. Microbial etiology of periodontitis. Periodontol 2000, 2004, 36: 14-26.

8. Haffajee AD, Socransky SS. Microbial etiological agents of destructive periodontal diseases. Periodontol 2000, 1994, 5: 78-111.

9. Chhour KL, Nadkarni MA, Byun R, Martin FE, Jacques NA, Hunter N. Molecular analysis of microbial diversity in advanced caries. J Clin Microbiol, 2005, 43: 843-849.

10. Ximenez-Fyvie LA, Haffajee AD, Socransky SS. Microbial composition of supra- and subgingival plaque in subjects with adult periodontitis. J Clin

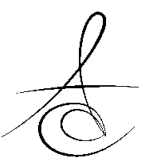


Periodontol, 2000, 27: 722-732.

11. Kuramitsu HK, He X, Lux R, Anderson MH, Shi W. Interspecies interactions within oral microbial communities. Microbiol Mol Biol Rev, 2007, 71: 653-670.

12. Marsh PD. Dental plaque: biological significance of a biofilm and community life-style. J Clin Periodontol, 2005, 32 Suppl 6: 7-15.

13. Takahashi N. Oral Microbiome Metabolism: From "Who Are They?" to "What Are They Doing?". J Dent Res, 2015, 94: 1628-1637.

14. Kolenbrander PE, Andersen RN, Blehert DS, Egland PG, Foster JS, Palmer RJ, Jr. Communication among oral bacteria. Microbiol Mol Biol Rev, 2002, 66: 486-505, table of contents.

15. Foster JS, Kolenbrander PE. Development of a multispecies oral bacterial community in a salivaconditioned flow cell. Appl Environ Microbiol, 2004, 70: 4340-4348.

16. Ritz HL. Microbial population shifts in developing human dental plaque. Arch Oral Biol, 1967, 12: 1561-1568.

17. Guo L, He X, Shi W. Intercellular communications in multispecies oral microbial communities. Front Microbiol, 2014, 5: 328.

18. Ng HM, Kin LX, Dashper SG, Slakeski N, Butler CA, Reynolds EC. Bacterial interactions in pathogenic subgingival plaque. Microb Pathog, 2016, 94: 6069.

19. Bowden $\mathrm{GH}$, Li YH. Nutritional influences on biofilm development. Adv Dent Res, 1997, 11: 81-99.

20. Dzink JL, Socransky SS, Haffajee AD. The predominant cultivable microbiota of active and inactive lesions of destructive periodontal diseases. J Clin Periodontol, 1988, 15: 316-323.

21. Grenier D, Mayrand D. Nutritional relationships between oral bacteria. Infect Immun, 1986, 53: 616-620.

22. Palmer RJ, Jr., Kazmerzak K, Hansen MC, Kolenbrander PE. Mutualism versus independence: strategies of mixed-species oral biofilms in vitro using saliva as the sole nutrient source. Infect Immun, 2001, 69: 5794-5804.

23. Loesche WJ, Rowan J, Straffon LH, Loos PJ. Association of Streptococcus mutants with human dental decay. Infect Immun, 1975, 11: 1252-1260.

24. Ihalin $R$, Loimaranta $V$, Lenander-Lumikari $M$, Tenovuo J. The sensitivity of Porphyromonas gingivalis and Fusobacterium nucleatum to different (pseudo)halide-peroxidase combinations compared with mutans streptococci. J Med Microbiol, 2001, 50: 42-48.

25. Hillman JD, Socransky SS, Shivers M. The relationships between streptococcal species and periodontopathic bacteria in human dental plaque. Arch Oral Biol, 1985, 30: 791-795.

26. Stacy A, Everett J, Jorth $P$, Trivedi U, Rumbaugh $\mathrm{KP}$, Whiteley $\mathrm{M}$. Bacterial fight-and-flight responses enhance virulence in a polymicrobial infection. Proc Natl Acad Sci U S A, 2014, 111: 7819-7824.

27. Mikx FH, Van der Hoeven JS. Symbiosis of Streptococcus mutans and Veillonella alcalescens in mixed continuous cultures. Arch Oral Biol, 1975, 20: 407-410.

28. Egland PG, Palmer RJ, Jr., Kolenbrander PE. Interspecies communication in Streptococcus gordonii-Veillonella atypica biofilms: signaling in flow conditions requires juxtaposition. Proc Natl Acad Sci U S A, 2004, 101: 16917-16922.

29. Diaz PI, Zilm PS, Rogers AH. Fusobacterium nucleatum supports the growth of Porphyromonas gingivalis in oxygenated and carbon-dioxidedepleted environments. Microbiology, 2002, 148: 467-472.

30. Takahashi N. Acid-neutralizing activity during amino acid fermentation by Porphyromonas gingivalis, Prevotella intermedia and Fusobacterium nucleatum. Oral Microbiol Immunol, 2003, 18: 109-113.

31. Gibbons RJ, Nygaard M. Interbacterial aggregation of plaque bacteria. Arch Oral Biol, 1970, 15: 13971400.

32. Vesey PM, Kuramitsu HK. Genetic analysis of Treponema denticola ATCC 35405 biofilm formation. Microbiology, 2004, 150: 2401-2407.

33. Sharma A, Inagaki S, Sigurdson W, Kuramitsu HK. Synergy between Tannerella forsythia and Fusobacterium nucleatum in biofilm formation. Oral Microbiol Immunol, 2005, 20: 39-42.

34. Orth RK, O'Brien-Simpson NM, Dashper SG, Reynolds EC. Synergistic virulence of Porphyromonas gingivalis and Treponema denticola in a murine periodontitis model. Mol Oral Microbiol, 2011, 26: 229-240.

35. Lovelock JE. A physical basis for life detection experiments. Nature, 1965, 207: 568-570.

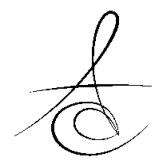


36. Wang BY, Kuramitsu HK. Interactions between oral bacteria: inhibition of Streptococcus mutans bacteriocin production by Streptococcus gordonii. Appl Environ Microbiol, 2005, 71: 354-62.

37. Yoneda M, Hirofuji T, Anan $H$, Matsumoto A, Hamachi T, Nakayama K, Maeda K. Mixed infection of Porphyromonas gingivalis and Bacteroides forsythus in a murine abscess model: involvement of gingipains in a synergistic effect. J Periodontal Res, 2001, 36: 237-243.

38. Ebersole JL, Feuille F, Kesavalu L, Holt SC. Host modulation of tissue destruction caused by periodontopathogens: effects on a mixed microbial infection composed of Porphyromonas gingivalis and Fusobacterium nucleatum. Microb Pathog, 1997, 23: 23-32.

39. Kesavalu L, Holt SC, Ebersole JL. Virulence of a polymicrobic complex, Treponema denticola and Porphyromonas gingivalis, in a murine model. Oral Microbiol Immunol, 1998, 13: 373-377.

40. Chen PB, Davern LB, Katz J, Eldridge JH, Michalek $\mathrm{SM}$. Host responses induced by co-infection with Porphyromonas gingivalis and Actinobacillus actinomycetemcomitans in a murine model. Oral Microbiol Immunol, 1996, 11: 274-281.

41. Chatterjee C, Paul M, Xie L, van der Donk WA. Biosynthesis and mode of action of lantibiotics. Chem Rev, 2005, 105: 633-684.

42. Qi F, Chen $P$, Caufield PW. The group I strain of Streptococcus mutans, UA140, produces both the lantibiotic mutacin I and a nonlantibiotic bacteriocin, mutacin IV. Appl Environ Microbiol, 2001, 67: 15-21.

43. Kreth J, Merritt J, Shi W, Qi F. Competition and coexistence between Streptococcus mutans and Streptococcus sanguinis in the dental biofilm. ] Bacteriol, 2005, 187: 7193-203.

44. Upton M, Tagg JR, Wescombe P, Jenkinson HF. Intra- and interspecies signaling between Streptococcus salivarius and Streptococcus pyogenes mediated by SalA and SalA1 lantibiotic peptides. J Bacteriol, 2001, 183: 3931-8.

45. Hoffman L. DAD, Bader M. and Miller S. Microbial Recognition of Antibiotics: Ecological, Physiological, and Therapeutic Implications. Microbe, 2007, 2: 175-82.

46. Teanpaisan R, Baxter AM, Douglas CW. Production and sensitivity of bacteriocin-like activity among
Porphyromonas gingivalis, Prevotella intermedia and $\mathrm{Pr}$. nigrescens strains isolated from periodontal sites. J Med Microbiol, 1998, 47: 5859.

47. Kara D, Luppens SB, Cate JM. Differences between single- and dual-species biofilms of Streptococcus mutans and Veillonella parvula in growth, acidogenicity and susceptibility to chlorhexidine. Eur J Oral Sci, 2006, 114: 58-63.

48. Takada K, Hirasawa M, Ikeda T. Isolation and purification of bacteriocin from Prevotella intermedia (Bacteroides intermedius). J Periodontol, 1991, 62: 439-44.

49. Nakamura T, Shibata Y, Shimura R, Fujimura S. Isolation and properties of the Capnocytophaga ochracea bacteriocin. Oral Microbiol Immunol, 1992, 7: 96-9.

50. Hammond BF, Lillard SE, Stevens RH. A bacteriocin of Actinobacillus actinomycetemcomitans. Infect Immun, 1987, 55: 686-91.

51. LiPuma JJ, Richman H, Stull TL. Haemocin, the bacteriocin produced by Haemophilus influenzae: species distribution and role in colonization. Infect Immun, 1990, 58: 1600-5.

52. Avila JEGJaCMJ. Bacteriocin-like activity of oral Fusobacterium nucleatum isolated from human and nonhuman primates. . Rev. Microbiol., 1999, 30: 342-6.

53. Apolonio AC, Carvalho MA, Ribas RN, Sousa-Gaia LG, Santos KV, Lana MA, Nicoli JR, Farias LM. Production of antagonistic substance by Eikenella corrodens isolated from the oral cavity of human beings with and without periodontal disease. J Appl Microbiol, 2007, 103: 245-51.

54. Seshadri R, Myers GS, Tettelin $H$, Eisen JA, Heidelberg JF, Dodson RJ, Davidsen TM, DeBoy RT, Fouts DE, Haft DH, Selengut J, Ren Q, Brinkac LM, Madupu R, Kolonay J, Durkin SA, Daugherty SC, Shetty J, Shvartsbeyn A, Gebregeorgis E, Geer K, Tsegaye G, Malek J, Ayodeji B, Shatsman S, McLeod MP, Smajs D, Howell JK, Pal S, Amin A, Vashisth P, McNeill TZ, Xiang Q, Sodergren E, Baca E, Weinstock GM, Norris SJ, Fraser CM, Paulsen IT. Comparison of the genome of the oral pathogen Treponema denticola with other spirochete genomes. Proc Natl Acad Sci U S A, 2004, 101: 5646-51.

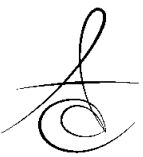


55. Kreth J, Merritt J, Shi W, Qi F. Co-ordinated bacteriocin production and competence development: a possible mechanism for taking up DNA from neighbouring species. Mol Microbiol, 2005, 57: 392-404.

56. Merritt J, Kreth J, Shi W, Qi F. LuxS controls bacteriocin production in Streptococcus mutans through a novel regulatory component. Mol Microbiol, 2005, 57: 960-9.

57. Roberts AP, Mullany P. Genetic basis of horizontal gene transfer among oral bacteria. Periodontol 2000, 2006, 42: 36-46.

58. Mahajan A, Singh B, Kashyap D, Kumar A, Mahajan $P$. Interspecies communication and periodontal disease. ScientificWorldJournal, 2013, 2013: 765434.

59. Roe DE, Braham PH, Weinberg A, Roberts MC. Characterization of tetracycline resistance in Actinobacillus actinomycetemcomitans. Oral Microbiol Immunol, 1995, 10: 227-32.

60. Sztajer H, Szafranski SP, Tomasch J, Reck M, Nimtz $M$, Rohde $M$, Wagner-Dobler I. Crossfeeding and interkingdom communication in dualspecies biofilms of Streptococcus mutans and Candida albicans. ISME J, 2014, 8: 2256-2271.

61. Roberts AP, Cheah G, Ready D, Pratten J, Wilson M, Mullany P. Transfer of TN916-like elements in microcosm dental plaques. Antimicrob Agents Chemother, 2001, 45: 2943-6.

62. Li YH, Lau PC, Lee JH, Ellen RP, Cvitkovitch DG. Natural genetic transformation of Streptococcus mutans growing in biofilms. J Bacteriol 2001, 183: 897-908.

63. Tribble GD, Garza JJ, Yeung VL, Rigney TW, Dao $\mathrm{DH}$, Rodrigues $\mathrm{PH}$, Walker CB, Smith CJ. Genetic analysis of mobile tetQ elements in oral Prevotella species. Anaerobe 2010; 16: 604-9.

64. Willi K, Sandmeier H, Asikainen S, Saarela M, Meyer J. Occurrence of temperate bacteriophages in different Actinobacillus actinomycetemcomitans serotypes isolated from periodontally healthy individuals. Oral Microbiol Immunol, 1997, 12: 406.

65. Huang R, Li M, Gregory RL. Bacterial interactions in dental biofilm. Virulence, 2011, 2: 435-44.

66. Taga ME, Semmelhack JL, Bassler BL. The LuxSdependent autoinducer $\mathrm{AI}-2$ controls the expression of an $A B C$ transporter that functions in
AI-2 uptake in Salmonella typhimurium. Mol Microbiol, 2001, 42: 777-93.

67. Cuadra-Saenz G, Rao DL, Underwood AJ, Belapure SA, Campagna SR, Sun Z, Tammariello S, Rickard $\mathrm{AH}$. Autoinducer-2 influences interactions amongst pioneer colonizing streptococci in oral biofilms. Microbiology, 2012, 158: 1783-95.

68. He J, Yarbrough DK, Kreth J, Anderson MH, Shi W, Eckert R. Systematic approach to optimizing specifically targeted antimicrobial peptides against Streptococcus mutans. Antimicrob Agents Chemother, 2010, 54: 2143-51.

69. Dashper SG, Seers CA, Tan KH, Reynolds EC. Virulence factors of the oral spirochete Treponema denticola. J Dent Res, 2011, 90: 691-703.

70. Ramsey MM, Rumbaugh KP, Whiteley M. Metabolite cross-feeding enhances virulence in a model polymicrobial infection. PLoS Pathog, 2011, 7: e1002012.

\author{
Yazışma Adresi \\ Zeliha AYTEKİN \\ Akdeniz Üniversitesi \\ Diş hekimliği Fakültesi \\ Periodontoloji A.B.D \\ phone:05078442459 \\ E-mail: zelihaaytekin06@gmail.com
}

